\title{
Robust scalable synthesis of a bis-urea derivative forming thixotropic and cytocompatible supramolecular hydrogels
}

\author{
Laurens A. J. Rutgeerts, ${ }^{\ddagger a}$ Al Halifa Soultan, ${ }^{\ddagger a b c}$ Ramesh Subramani, ${ }^{\text {B }}$ Burak Toprakhisar, ${ }^{\text {be Herman }}$ \\ Ramon, ${ }^{d}$ Monissa C. Paderes, ${ }^{a}$ Wim M. De Borggraeve ${ }^{* a}$ and Jennifer Patterson ${ }^{*}$ bcf
}

Synthetic hydrogels address a need for affordable, industrially scalable scaffolds for tissue engineering. Herein, a novel low molecular weight gelator is reported that forms self-healing supramolecular hydrogels. Its robust synthesis can be performed in a solvent-free manner using ball milling. Strikingly, encapsulated cells spread and proliferate without specific cell adhesion ligands in the nanofibrous material.

Hydrogels are 3D water-swollen materials that, due to similarities with biological tissues, have been increasingly used in biomedical applications such as tissue engineering and regenerative medicine (TERM) and drug delivery. ${ }^{1,} 2$ Many natural hydrogels as well as some synthetic ones consist of a network that is formed by non-covalent bonds. ${ }^{1,3} \mathrm{~A}$ special class of non-covalent gelators are the low molecular weight gelators (LMWGs). These are small molecules that self-assemble into supramolecular polymers, which in turn form a network of entangled nanofibers, entrapping solvent to form a gel. The nanofibrous nature of the resulting 3D network can mimic the extracellular matrix (ECM) in terms of architecture and mechanics, which makes LMWG based hydrogels interesting candidates as scaffolds for cells. ${ }^{3,} 4$ Among LMWGs, bis-urea based gelators are interesting due to their straightforward synthesis and flexibility towards structural modification. However, the majority of bis-urea based LMWGs synthesized to date self-assembled into fibers and formed gels in organic solvents (organogels) ) $^{5-8}$ and/or in the presence of metal ions (metallogels),, 10 which has limited their applicability in TERM

\footnotetext{
a. Department of Chemistry, KU Leuven, 3001 Leuven, Belgium.

b. Department of Materials Engineering, KU Leuven, 3001 Leuven, Belgium.

c. Prometheus, KU Leuven, 3000 Leuven, Belgium.

d. Department of Biosystems, KU Leuven, 3001 Leuven, Belgium

e. Stem Cell Institute, KU Leuven, 3000 Leuven, Belgium.

f. Department of Imaging and Pathology, KU Leuven, 3000 Leuven, Belgium.

¥ These authors contributed equally.

* Corresponding authors: wim.deborggraeve@kuleuven.be (W.M.D.B), pattersn@alumni.princeton.edu (J.P.)

† Electronic Supplementary Information (ESI) available: detailed synthesis and characterization methods, supplementary figures (NMR, FTIR, AFM, rheology), supplementary movies 1 and 2. See DOI: 10.1039/x0xx00000x
}

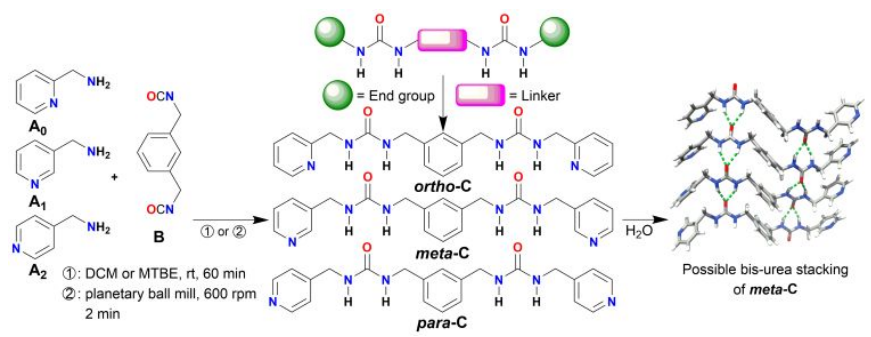

Fig. 1 Synthesis of the novel low molecular weight hydrogelator, meta-C, and derivatives, para-C and ortho-C (characterization of the compounds: Fig. S1; Fig. S3; Fig. S4, ESI+).

due to cytotoxicity concerns. Nonetheless, a bis-urea organogelator was transformed into a hydrogelator, in $\mathrm{Ca}^{2+}$ containing buffers, by incorporating carboxylate groups. ${ }^{11}$ However, the resulting hydrogels were not tested for biological applications.

Based on the generalized structure derived from the literature examples of bis-urea gelators shown in Fig. 1, we synthesized a series of three pyridine-containing compounds (Fig. 1 structures $\mathrm{C}$ ) where the nitrogen atom in the pyridyl group was shifted from the ortho (ortho-C) over the meta (meta-C) to the para (para-C) position. Strikingly, meta-C was able to form a hydrogel in the absence of added ions. Hydrogen bonding between the urea moieties ${ }^{5}$ most probably is responsible for self-assembly with the possible stacking shown in Fig. 1.

The bis-urea compounds were synthesized in quantitative yields via reaction of picolylamine derivatives (Fig. 1 structure $\mathbf{A}_{\mathbf{0}}, \mathbf{A}_{\mathbf{1}}$, or $\mathbf{A}_{\mathbf{2}}$ ) with $m$-xylylene diisocyanate (Fig. 1 structure $\mathbf{B}$ ) (see methods in ESIt). Solvent-free assembly of the gelator was possible using a planetary ball mill, as exemplified by the synthesis of meta-C with full conversion of B (Fig. S2, ESI+). Ball milling is an emerging green industrial technique, which ensures efficient mixing of the starting materials in the absence of solvent. ${ }^{12}$ The simplicity of preparation of our material is in strong contrast with the complexity (cost, number of steps, purification, etc.) associated with the production of peptide- 


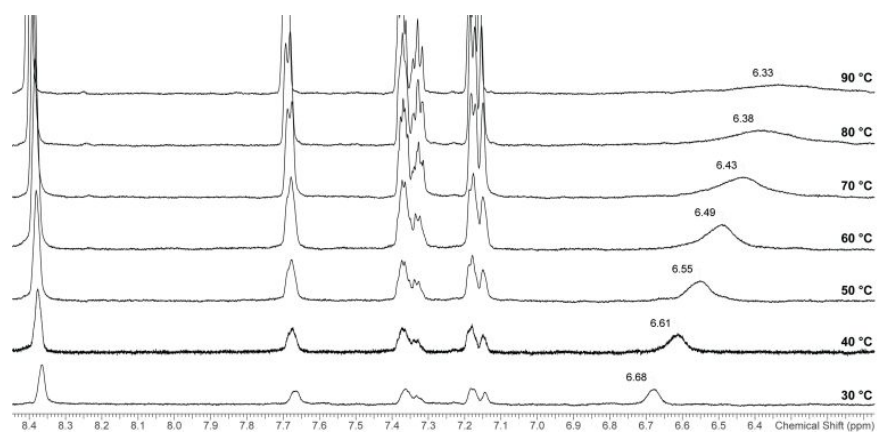

Fig. $2 \mathrm{VT}{ }^{1} \mathrm{H}$ NMR spectra of meta-C, showing peak shifting and broadening of the $\mathrm{NH}$ proton $\left(\delta=6.68 \mathrm{ppm}\right.$ at $\left.30^{\circ} \mathrm{C}\right)$.

based LMWGs, which are the most common type of LMWGs used for biomedical applications. ${ }^{3,13}$

Hydrogels of meta-C were prepared by dissolving the compound in deionized water at $100{ }^{\circ} \mathrm{C}$ and sonicating the resulting aqueous solution during cooling, using an ultrasonic tip immersed in the mixture (Supplementary Movie 1, ESI†). We evaluated the gelation by vial inversion tests, as commonly reported. ${ }^{14}$ Hydrogels could be formed in deionized water, phosphate buffered saline (PBS), Dulbecco's Modified Eagle's Medium, and growth medium at concentrations ranging from 0.3 to 1.0 wt.\%. Below and above this concentration range, we observed flocculation and precipitate formation, respectively. In contrast, ortho-C and para-C failed to form hydrogels under these conditions and precipitated during cooling. Interestingly, meta- $C$ could form hydrogels both in the presence and absence of ions without the addition of organic solvent. This clearly distinguishes these compounds from structurally very similar metallogelators described by Piepenbrock et al. ${ }^{10}$ that required $\mathrm{Ag}^{+}$ions to form gels in $\mathrm{THF} / \mathrm{H}_{2} \mathrm{O}$, limiting their applicability as biomaterials. This initially suggested that meta- $C$ should be suitable for biomedical applications, motivating its additional characterization.

To confirm that gelation was induced by self-assembly of meta-C, we used variable temperature (VT) ${ }^{1} \mathrm{H}$ NMR. The signals corresponding to the protons of the urea groups shifted upfield from $\delta=6.6$ to $6.3 \mathrm{ppm}$ upon heating from 30 to $90{ }^{\circ} \mathrm{C}$ (Fig. 2), indicating disruption of the hydrogen bonds. We also observed peak broadening for these signals, in agreement with increased chemical exchange of the now solvent-exposed urea $\mathrm{NH}$ protons upon heating. Further, peak narrowing of the signals from the aromatic protons $(\delta=8.4-7.1 \mathrm{ppm})$ occurred at increased temperature, signifying that more of the compound was dissolved. Comparing these observations with literature ${ }^{15}$, 16 allowed us to conclude that self-assembled structures were present in the gel state and started breaking up at elevated temperature corresponding to a gel-sol transition.

Scanning electron microscopy (SEM) performed on xerogels of meta-C and dried precipitates of ortho-C and para-C demonstrated that all compounds self-assembled in aqueous solutions; however, the observed architectures were different. SEM of ortho-C showed a network of intertwined bundles of nanofibers (Fig. 3a). Likewise, images of meta-C (Fig. 3b) showed the presence of this kind of network, but the nanofiber bundles appeared larger in size compared to those of ortho-C (average nanofiber width: $250 \mathrm{~nm}$ vs. $\sim 90 \mathrm{~nm}$, respectively).

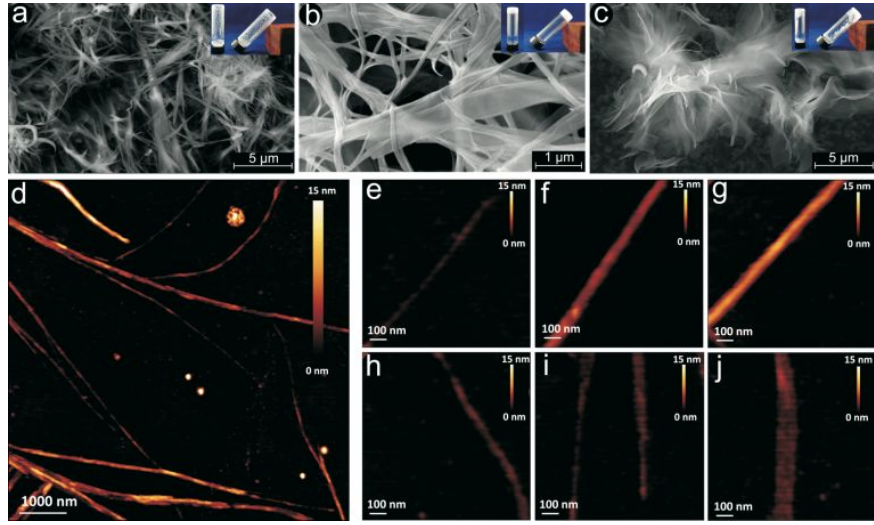

Fig. 3 (a-c) Representative SEM images of structures formed by ortho-C (a, dried precipitate), meta- $\mathrm{C}(\mathrm{b}, \mathrm{xerogel})$, and para- $\mathrm{C}$ ( $\mathrm{c}$, dried precipitate). The insets show the respective precipitates/hydrogels during vial inversion. (d) AFM height image of nanofibrils/nanofibers of meta-C. (e-j) Representative higher resolution AFM images of nanofibrils/nanofibers of meta-C showing variation in dimensions.

On the other hand, para-C formed a sheet-like morphology (Fig. 3c). These differences in morphology, in combination with the fact that only meta-C could form hydrogels, indicate that the position of the nitrogen in the pyridyl end groups plays a crucial role during self-assembly. To examine the nanofibers' structure at higher resolution, atomic force microscopy (AFM) was performed on hydrogels made from meta-C in deionized water, after further dilution and drying. The images confirmed the presence of nanofibers that were composed of nanofibrils (Fig. $3 \mathrm{~d}$ ). The height of the structures varied from 0.9 to $13.1 \mathrm{~nm}$, and their width ranged from 19 to $135 \mathrm{~nm}$. Higher resolution images showed that, in some cases, both the height and width of the structures increased (Fig. 3e-g). In other cases, the width of the structures increased while their height remained $\sim 2-3 \mathrm{~nm}$ (Fig. $3 \mathrm{~h}-\mathrm{j}$ ), leading to a ribbon-like morphology. In a detailed dimensional analysis of the nanofibers/nanofibrils (Fig. S5, $\mathrm{ESI}+$ ), the height and the width of the structures showed a linear correlation $\left(R^{2}=0.72\right)$, which further confirms that nanofibrils could self-assemble orthogonally to their long axis and suggests a possible mechanism for nanofiber formation. Other valuable structural information such as thinning or splitting of nanofibers/nanofibrils could also be observed (Fig. S5, ESI†), indicating the hierarchical interactions between nanofibrils.

Our hypothesis is that moving the nitrogen of the pyridyl end group from the ortho to para position promotes orthogonal self-assembly of the nanofibrils thus increasing the width of the nanofibers and eventually forming sheets. We propose that the orthogonal self-assembly occurs either through bridging water molecules ${ }^{17}$ that insert between the monomer units and link the pyridyl groups via hydrogen bonding or through $\mathrm{C}-\mathrm{H} \cdots \mathrm{N}$ hydrogen bonding ${ }^{18}$ between the pyridyl groups. Taking into account that only meta-C forms hydrogels under the conditions explored, it appears that orthogonal self-assembly plays a prominent role in nanofiber formation and their subsequent entanglement to form the hydrogel. Nanofibrous materials mimic the network topology of the natural ECM, ${ }^{19}$ and the fiber dimensions measured here are within the range of those measured for collagen and other ECM components (5-500 $\mathrm{nm}) \cdot{ }^{20-22}$ Further, meta-C appears to form hierarchical assemblies, which begin to mimic how collagen is organized. ${ }^{22,}$ 

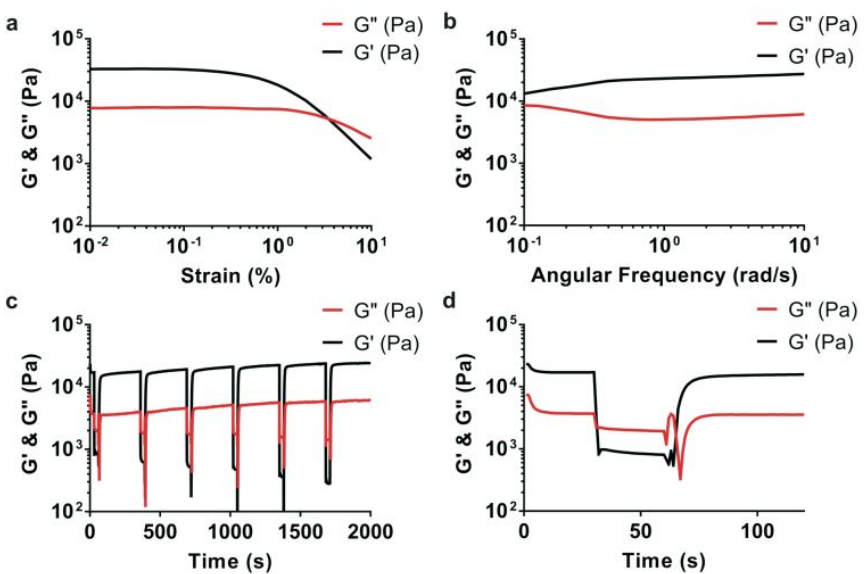

Fig. 4 Shear rheology (performed on 0.8 wt.\% hydrogels of meta-C in growth medium) showing the average of three independent measurements of the storage $\left(G^{\prime}\right)$ and loss $\left(G^{\prime \prime}\right)$ moduli from (a) strain sweeps, (b) frequency sweeps and (c, d) dynamic strain amplitude tests (alternating between $0.08 \%$ and $10 \%$ strain). The graph in (d) is an expanded version of the first $120 \mathrm{~s}$ from (c). Graphs including error bars showing the standard deviation of the three replicates can be found in Fig. S6 in the ESIt.

23 Thus, we envision that the nanofibrous character of these hydrogels will enhance their biological performance.

Supramolecular hydrogels have the potential to flow under mechanical stress and re-form under static conditions, indicating thixotropic (i.e., self-healing) behavior, which would allow for minimally invasive delivery of the material through a syringe ${ }^{24}$ as well as for processing by extrusion-based bioprinting. ${ }^{25}$ Further, such dynamic systems can be remodeled by cells, ${ }^{13}$ and recent research has shown that stress relaxation influences the behavior of cells encapsulated within hydrogels. ${ }^{26}$ Strain and frequency sweep experiments on hydrogels of meta-C, made using growth medium, confirmed the dynamic nature of the interactions leading to hydrogel formation (Fig. 4). At low strain, the storage ( $\left.G^{\prime}\right)$ and loss ( $\left.G^{\prime \prime}\right)$ moduli remained independent of the applied strain, presenting values of $17800 \pm 900 \mathrm{~Pa}$ and $4780 \pm 210 \mathrm{~Pa}$, respectively, with $\mathrm{G}^{\prime}>\mathrm{G}^{\prime \prime}$ demonstrating the solid-like behavior of the hydrogel. Strain sweep measurements revealed shear thinning behavior with the gel network breaking up at $0.3 \%$ of strain when $\mathrm{G}^{\prime}$ began to decrease (Fig. 4a; Fig. S6, ESIt). Furthermore, the frequency-dependent rheology of the hydrogels, characterized by a decrease in $G^{\prime}$ with decreasing frequency and minimum for G" at low frequencies (Fig. 4b; Fig. S6, ESI+), showed that the hydrogels exhibited stress relaxation, which could also be observed in Fig. 4c-d where G' and G" decreased during the first few seconds of the measurement. The self-healing behavior of the meta-C hydrogels was demonstrated by a dynamic strain amplitude test (Fig. 4c-d; Fig. S6, ESI + ). The hydrogels had the ability to become fluid-like when applying a strain of $10 \%$ since $\mathrm{G}^{\prime}$ decreased to a value below $\mathrm{G}^{\prime \prime}$ and to fully recover when decreasing the strain to $0.08 \%$. Moreover, the alternation of high strain break up and low strain recovery could be repeated many times with full return of $\mathrm{G}^{\prime}$ after each cycle (Fig. 4c). Further confirming the self-healing behavior, complete recovery of 'G' was observed when alternating between even higher strain (100\%) and $0.08 \%$ strain (Fig. S6, ESI + ). Taken together, these results suggested that the hydrogels should reform after passage through a needle, which is demonstrated in
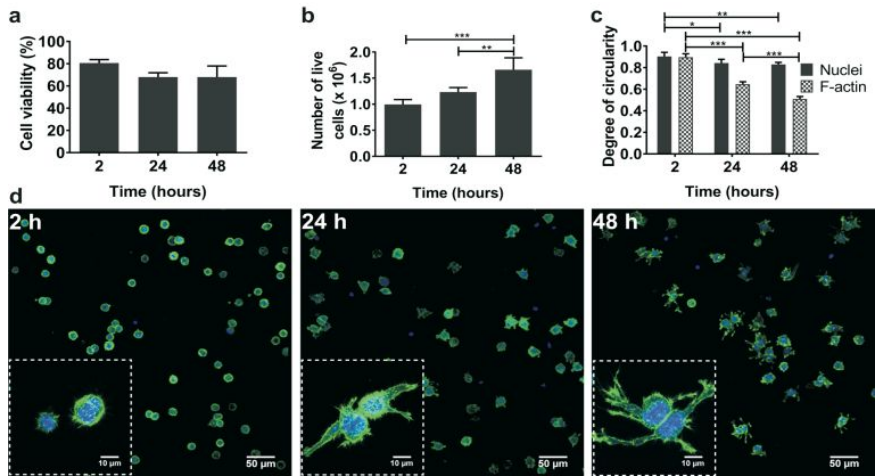

Fig. 5 (a) Quantification of cell viability by trypan blue exclusion ( $p$-values insignificant). (b) Quantification of the live cell number per $1 \mathrm{~mL}$ hydrogel. (c) Circularity measurements for nuclei (as a control) and F-actin signals. (d) Representative confocal image stacks showing cell morphology in the hydrogels after 2,24 , and $48 \mathrm{~h}$ of in vitro culture. The actin cytoskeleton is in green, and the nucleus is in blue. The dashed squares represent higher resolution images showing detailed cell morphology. Data are presented as mean and standard deviation of $n=4$ for (a) and (b) and $n=5$ random locations $\left(500 \times 500 \mu^{2}\right)$ per time point for (c), * $p<0.05,{ }^{* *} p<0.01$, and $* * * p<0.001$, one-way ANOVA with Bonferroni's multiple comparisons test.

Supplementary Movie 2 (see ESI+) and further proves the potential for using these hydrogels as injectable materials in TERM.

Finally, cells were encapsulated in meta-C hydrogels by mixing pre-formed hydrogels made in growth medium with a cell suspension. This procedure allowed the gels to re-form and serve as a 3D matrix for cell growth. First, we evaluated the survival of encapsulated L929 fibroblasts, which are standardly used in cytotoxicity assays. For an initial seeding density of 1.2 $\times 10^{6}$ cells $/ \mathrm{mL}$, a high viability of around $80 \%$ was measured after $2 \mathrm{~h}$ and was maintained over $48 \mathrm{~h}$ of culture (Fig. 5a, insignificant $p$-value). Live/Dead assays also confirmed the high viability of the cells (data not shown). These results indicated that the meta-C hydrogel was non-toxic. Further, the total number of cells in the hydrogels at $2 \mathrm{~h}$ was consistent with the original seeding density, suggesting a high encapsulation efficiency. Moreover, the live cell number increased significantly over time, approximately $70 \%$ in 48 h (Fig. 5b), which indicated that cells were able to proliferate in the hydrogels. This proliferation rate is similar to that observed for L929 fibroblasts encapsulated in a self-healing chitosan-based hydrogel ${ }^{27}$ and suggests that our fibrillar hydrogel can be remodeled.

Additionally, meta-C hydrogels allowed the encapsulated cells to spread over time (Fig. 5d). Confocal microscopic images of the actin cytoskeleton showed that the cells, which were initially spherical at $2 \mathrm{~h}$, started to form extended filaments after $24 \mathrm{~h}$ of culture. After $48 \mathrm{~h}$, the cell morphology became even more spread. As a quantitative metric, cell circularity shifted towards zero over time, implying the increased tendency of the fibroblasts to spread in the hydrogels (Fig. 5c). These results are interesting because the hydrogel is formed without bioactive cues, such as cell adhesion ligands, in the matrix itself. Lack of adhesion ligands is a common limitation of synthetic biomaterials, and their addition is often required to promote cell attachment. ${ }^{28-30}$ In our case, we hypothesize that serum proteins from the medium deposit on the nanofibers or are trapped in the network to mediate cell attachment, as has 
been observed with other nanofibrous scaffolds, ${ }^{31}$ but this would need to be further studied. AFM images of hydrogels formed in growth medium confirmed that nanofibers were still formed; however, there was increased background from salts and protein (Fig. S5, ESI + ). The nanofibrous morphology may also promote cell spreading by topographical cues, and the physically entangled nanofibers provide a mechanism for cells to remodel the network. Further, our findings are in agreement with the work of Mooney's group who observed enhanced 3T3 fibroblast spreading, which was attributed to the stress relaxing behavior of their alginate-based hydrogel. ${ }^{26}$ Overall, these data highlight the potential of our material as a scaffold for 3D cell expansion, and the non-covalent network structure of the hydrogel allows for easy recovery of the expanded cells since the network can be disrupted by dilution or the application of mechanical stress.

Herein, we demonstrate that a synthetic low molecular weight bis-urea based hydrogelator, meta-C, forms nanofibrous and thixotropic hydrogels, which have potential in the fields of TERM and drug delivery. The robustness and scalability of the synthesis, along with the use of readily available starting materials, make this material commercially interesting. The nanofibrous network provides a biomimetic architecture; however, the mechanism of self-assembly also explaining the exact role of the position of the nitrogen atom in the pyridine ring has to be further elucidated. Furthermore, the resulting hydrogel is injectable, which would allow for minimally invasive administration. Cytotoxicity assays demonstrate that the hydrogel is cytocompatible and permits cell spreading and proliferation, which is unexpected because the chemical structure does not contain inherent cell adhesion ligands. As future work, this material could be explored for the expansion and differentiation of different cell types to further evaluate its potential as a 3D scaffold. Overall, we provide evidence that the use of small and well-defined molecules to generate supramolecular synthetic hydrogels represents a promising and affordable alternative to the commonly used polymeric or peptide-based hydrogels. We are convinced that this work will motivate the scientific community not only to investigate this specific LMWG but also to explore other non-peptide-based LMWGs for biomedical applications.

This work was funded by KU Leuven grants OT/14/067 (W.M.D.B.), C32/16/006 (W.M.D.B.), CREA/13/017 (J.P.), and IDO/13/016 (H.R. and J.P.). A.H.S. was supported by a fellowship from the European Union's 7th Framework Programme under REA grant agreement no. 608765. The authors acknowledge P. Moldenaers and M. Meerts for use of the rheometers and I. Martínez García for helpful suggestions on the interpretation of the rheological data. The Hercules Foundation funded the 400 MHz NMR spectrometer (AKUL/13/11), Zeiss LSM 780 confocal microscope (AKUL/11/37), and JPK Nanowizard ${ }^{\circledR}$ III (HER/09/021). The authors thank T. Van Gerven and S. Van Loy for assistance with ball milling; K. A. Leonidakis and D. Lambrechts for help with confocal microscopy; and J. Demaerel, P. Gilles, and S. Van Mileghem for help with the movies.

\section{Conflicts of interest}

There are no conflicts to declare.

\section{References}

1. A. S. Hoffman, Adv. Drug Deliv. Rev., 2012, 64, 18-23.

2. J. Patterson, M. M. Martino and J. A. Hubbell, Mater. Today, 2010, 13, 14-22.

3. H. W. Ooi, S. Hafeez, C. A. van Blitterswijk, L. Moroni and M. B. Baker, Mater. Horiz., 2017, 4, 1020-1040.

4. C. D. Jones and J. W. Steed, Chem. Soc. Rev., 2016, 45, 65466596.

5. J. H. van Esch, F. Schoonbeek, M. de Loos, H. Kooijman, A. L. Spek, R. M. Kellogg and B. L. Feringa, Chem. Eur. J., 1999, 5, $937-$ 950.

6. A. E. Hooper, S. R. Kennedy, C. D. Jones and J. W. Steed, Chem. Commun., 2016, 52, 198-201.

7. Y. Jeong, K. Hanabusa, H. Masunaga, I. Akiba, K. Miyoshi, S. Sakurai and K. Sakurai, Langmuir, 2005, 21, 586-594.

8. S. van der Laan, B. L. Feringa, R. M. Kellogg and J. van Esch, Langmuir, 2002, 18, 7136-7140.

9. M.-O. M. Piepenbrock, N. Clarke and J. W. Steed, Langmuir, 2009, 25, 8451-8456.

10. M.-O. M. Piepenbrock, N. Clarke and J. W. Steed, Soft Matter, 2011, 7, 2412-2418.

11. L. A. Estroff and A. D. Hamilton, Angew. Chem. Int. Ed., 2000, 39, 3447-3450.

12. A. Stolle, T. Szuppa, S. E. Leonhardt and B. Ondruschka, Chem. Soc. Rev., 2011, 40, 2317-2329.

13. K. J. Skilling, F. Citossi, T. D. Bradshaw, M. Ashford, B. Kellam and M. Marlow, Soft Matter, 2014, 10, 237-256.

14. J. Brinksma, B. L. Feringa, R. M. Kellogg, R. Vreeker and J. van Esch, Langmuir, 2000, 16, 9249-9255.

15. A.-L. Alanne, M. Lahtinen, M. Lofman, P. Turhanen, E. Kolehmainen, J. Vepsalainen and E. Sievanen, J. Mater. Chem. B, 2013, 1, 6201-6212.

16. Y. E. Shapiro, Prog. Polym. Sci., 2011, 36, 1184-1253.

17. S. Schlücker, R. K. Singh, B. P. Asthana, J. Popp and W. Kiefer, J. Phys. Chem. A, 2001, 105, 9983-9989.

18. C. Rotger, B. Soberats, D. Quiñonero, A. Frontera, P. Ballester, J. Benet-Buchholz, P. M. Deyà and A. Costa, Eur. J. Org. Chem., 2008, 2008, 1864-1868.

19. D.-H. Kim, P. P. Provenzano, C. L. Smith and A. Levchenko, J. Cell Biol., 2012, 197, 351-360.

T. Elsdale and J. Bard, J. Cell Biol., 1972, 54, 626-637.

21. A. Mujeeb, A. F. Miller, A. Saiani and J. E. Gough, Acta Biomaterialia, 2013, 9, 4609-4617.

22. L. A. Smith and P. X. Ma, Colloids Surf. B, 2004, 39, 125-131.

23. K. Gelse, E. Pöschl and T. Aigner, Adv. Drug Deliv. Rev., 2003, 55, 1531-1546.

24. A. Hasan, A. Khattab, M. A. Islam, K. Abou Hweij, J. Zeitouny, R. Waters, M. Sayegh, M. M. Hossain and A. Paul, Adv. Sci., 2015, 2.

25. S. V. Murphy, A. Skardal and A. Atala, J. Biomed. Mater. Res. A, 2013, 101, 272-284.

26. O. Chaudhuri, L. Gu, D. Klumpers, M. Darnell, S. A. Bencherif, J. C. Weaver, N. Huebsch, H.-P. Lee, E. Lippens, G. N. Duda and D. J. Mooney, Nat. Mater., 2016, 15, 326-334.

27. Y. Li, Y. Zhang, F. Shi, L. Tao, Y. Wei and X. Wang, Colloids Surf. B, 2017, 149, 168-173.

28. J. A. Burdick and K. S. Anseth, Biomaterials, 2002, 23, 4315-4323.

29. P. Y. W. Dankers, M. C. Harmsen, L. A. Brouwer, M. J. A. Van Luyn and E. W. Meijer, Nat. Mater., 2005, 4, 568-574.

30. J. A. Rowley, G. Madlambayan and D. J. Mooney, Biomaterials, 1999, 20, 45-53.

31. K. M. Woo, V. J. Chen and P. X. Ma, J. Biomed. Mater. Res. A, 2003, 67A, 531-537. 


\section{Robust scalable synthesis of a bis-urea derivative forming thixotropic and cytocompatible supramolecular hydrogels}

Laurens A. J. Rutgeerts, ${ }^{\mathrm{a} \ddagger}$ Al Halifa Soultan,,${ }^{\mathrm{a}, \mathrm{b}, \mathrm{c}, 1 \ddagger}$ Ramesh Subramani, ${ }^{\mathrm{d}, 2}$ Burak Toprakhisar, ${ }^{\mathrm{b}, \mathrm{e}}$ Herman Ramon, ${ }^{\mathrm{d}}$ Monissa C. Paderes, ${ }^{\mathrm{a}, 3}$ Wim M. De Borggraeve ${ }^{\mathrm{a}^{*}}$ and Jennifer Patterson ${ }^{\mathrm{b}, \mathrm{c}, \mathrm{f}^{*}}$

a. Department of Chemistry, KU Leuven, 3001 Leuven, Belgium

b. Department of Materials Engineering, KU Leuven, 3001 Leuven, Belgium

c. Prometheus, KU Leuven, 3000 Leuven, Belgium

d. Department of Biosystems, KU Leuven, 3001 Leuven, Belgium

e. Stem Cell Institute, KU Leuven, 3000 Leuven, Belgium

f. Department of Imaging \& Pathology, KU Leuven, 3000 Leuven, Belgium

${ }^{*}$ These authors contributed equally to this work.

*Corresponding authors. E-mail addresses: pattersn@alumni.princeton.edu (Jennifer

Patterson); wim.deborggraeve@kuleuven.be (Wim De Borggraeve)

Present Affiliations:

${ }^{1}$ Department of Chemistry, Université du Québec à Montréal, Montreal, Canada

${ }^{2}$ Department of Food Processing Technology and Management, PSGR Krishnammal College for Women, Peelamedu, India

${ }^{3}$ Institute of Chemistry, University of the Philippines, Diliman, Philippines 


\section{Supplementary Methods}

Materials. 1,3-bis(isocyanatomethyl)benzene, > 98.0 \% (B), was purchased from TCI. 3$\begin{array}{llllllll}\text { (aminomethyl)pyridine, } & 99+ & \% & \left(\mathbf{A}_{1}\right) ; & 2-(\text { aminomethyl)pyridine, } & 99 & \% & \left(\mathbf{A}_{0}\right) ;\end{array}$ (aminomethyl)pyridine, $98 \%$ (A2); and dichloromethane (DCM), 99.8\%, Extra Dry stored over Molecular Sieves, Stabilized, AcroSeal ${ }^{\mathrm{TM}}$ were purchased from ACROS Organics. Deuterium oxide $\left(\mathrm{D}_{2} \mathrm{O}\right)$ and dimethyl sulfoxide- $d_{6}\left(\mathrm{DMSO}-d_{6}\right)$ were purchased from Sigma Aldrich.

Instrumentation. Ball milling experiments were performed using a Planetary Micro Mill, PULVERISETTE 7 premium line (Fritsch), equipped with a set of zirconium oxide grinding bowls $(80 \mathrm{~mL})$ filled with zirconium oxide grinding balls $(10 \mathrm{~mm}) .{ }^{1} \mathrm{H}$ NMR and ${ }^{13} \mathrm{C}$ NMR spectra were recorded on a Bruker Avance 400 spectrometer operating at $400 \mathrm{MHz}$ and $100 \mathrm{MHz}$ for the respective nuclei or on a Bruker Avance 600 spectrometer operating at $600 \mathrm{MHz}$ and 150 $\mathrm{MHz}$ for the respective nuclei. Chemical shifts are given in $\mathrm{ppm}(\delta)$ values relative to tetramethylsilane (TMS) or the residual solvent peak. The spectra were analyzed using ACD/ Spectrus Processor 2016.1.1 (Advanced Chemistry Development, Inc.). Fourier transform infrared (FTIR) spectra were recorded on a Bruker alpha-P FTIR spectrometer using OPUS 7.5: Build 7,5,18 (20140810) software (Bruker Optik GmbH). The spectra were analyzed using ACD/ Spectrus Processor 2016.1.1 (Advanced Chemistry Development, Inc.). Differential Scanning Calorimetry (DSC) measurements were recorded using a Mettler-Toledo DSC 822e under helium atmosphere from $25{ }^{\circ} \mathrm{C}$ to $250{ }^{\circ} \mathrm{C}$ with a heating rate of $10^{\circ} \mathrm{C} / \mathrm{min}$. Mass spectrometry (MS) was performed using a Thermo Electron LCQ Advantage apparatus (Thermo Scientific) equipped with an Agilent 1100 pump and injection system (Agilent Technologies). Spectra were acquired using a quadrupole orthogonal acceleration time-of-flight mass spectrometer Synapt G2 HDMS (Waters). Samples were infused at $3 \mu \mathrm{L} / \mathrm{min}$, and spectra were obtained in positive ionization mode with a resolution 
of 15000 (FWHM) using leucine encephalin as lock mass. Data were analyzed using Xcalibur software (Thermo Fisher Scientific Inc.).

\section{Synthesis of bis-urea compound meta-C (1,1'-(1,3-phenylenebis(methylene))bis(3-(pyridin-3-}

ylmethyl)urea)) in solution. A flame dried two-neck flask was charged with dry dichloromethane (DCM) and 1,3-bis(isocyanatomethyl)benzene ( $m$-xylylene diisocyanate, $\mathbf{B}$ in text) $(1 \mathrm{~g} ; 5.31 \mathrm{mmol})$ under nitrogen atmosphere. Pyridin-3-ylmethanamine (3-picolylamine, $\mathbf{A}_{\mathbf{1}}$ in text) $(1.149 \mathrm{~g} ; 10.63 \mathrm{mmol})$ was added dropwise while stirring. The mixture was allowed to stir for $1 \mathrm{~h}$ at room temperature. The product was filtered off as a white precipitate, washed with DCM, and dried under vacuum. 1,1'-(1,3-phenylenebis(methylene))bis(3-(pyridin-3ylmethyl)urea) (meta-C in text) was obtained in quantitative yield. The compound was characterized with ${ }^{1} \mathrm{H}$ NMR (Fig. S1a), ${ }^{13} \mathrm{C}$ NMR (Fig. S1b), FTIR (Fig. S1c), DSC (melting point, $\mathrm{T}_{\mathrm{m}}$ ), and MS (ESI).

${ }^{1} \mathrm{H}$ NMR $\left(400 \mathrm{MHz}\right.$, DMSO- $\left.d_{6}\right) \delta=4.20(\mathrm{~d}, \mathrm{~J}=6.02 \mathrm{~Hz}, 4 \mathrm{H}), 4.25(\mathrm{~d}, \mathrm{~J}=6.02 \mathrm{~Hz}, 4 \mathrm{H}), 6.45-$ $6.58(\mathrm{~m}, 4 \mathrm{H}), 7.08-7.14(\mathrm{~m}, 3 \mathrm{H}), 7.21-7.27(\mathrm{~m}, 1 \mathrm{H}), 7.34(\mathrm{dd}, \mathrm{J}=7.63,4.88 \mathrm{~Hz}, 2 \mathrm{H}), 7.65$ (br d, J = $7.78 \mathrm{~Hz}, 2 \mathrm{H}), 8.41-8.49(\mathrm{~m}, 4 \mathrm{H})$

${ }^{13} \mathrm{C}$ NMR (100 MHz, DMSO- $\left.d_{6}\right) \delta=40.7,43.0,123.4,125.3,125.7,128.2,134.8,136.4,140.8$, $147.9,148.6,158.1$

FTIR $\left(\mathrm{cm}^{-1}\right): v=3319(\mathrm{~N}-\mathrm{H}$ stretch$) ; 1609(\mathrm{C}=\mathrm{O}$ stretch $) ; 1565(\mathrm{~N}-\mathrm{H}$ bend $)$

$\mathrm{T}_{\mathrm{m}}: 198^{\circ} \mathrm{C}$

MS (ESI) m/z: Calculated mass for $\mathrm{C}_{22} \mathrm{H}_{24} \mathrm{~N}_{6} \mathrm{O}_{2}$ : 404.20; Found mass: $405.1[\mathrm{M}+\mathrm{H}]^{+}$ 
Solvent-free synthesis of meta-C using a planetary ball mill. Two grinding bowls (volume: 80 $\mathrm{mL}$, zirconium oxide) were each charged with 25 balls (diameter: $10 \mathrm{~mm}$, zirconium oxide) to obtain a $32 \%$ filling ratio. 1,3-bis(isocyanatomethyl)benzene ( $m$-xylylene diisocyanate, $\mathbf{B}$ in text) (0.500 g; $2.66 \mathrm{mmol})$ and pyridin-3-ylmethanamine (3-picolylamine, $\mathbf{A}_{\mathbf{1}}$ in text) (0.575 g; $5.31 \mathrm{mmol}$ ) were added to each bowl. Both bowls were closed and inserted in the planetary ball mill, which was operated at a rotational speed of 600 revolutions per minute (rpm) for the main disk (1200 rpm as the relative rotational speed for each grinding bowl) for $2 \mathrm{~min}$. The product (1,1'-(1,3-phenylenebis(methylene))bis(3-(pyridin-3-ylmethyl)urea) (meta-C in text) was recovered from the bowls as a solid. Quantitative conversion was confirmed via FTIR (Fig. S2).

Synthesis of bis-urea compound para-C (1,1'-(1,3-phenylenebis(methylene))bis(3(pyridin-4-ylmethyl)urea)). A flame dried two-neck flask was charged with dry DCM and 1,3-bis(isocyanatomethyl)benzene ( $m$-xylylene diisocyanate, B in text) (1 g; $5.31 \mathrm{mmol}$ ) under nitrogen atmosphere. Pyridin-4-ylmethanamine (4-picolylamine, $\mathbf{A}_{\mathbf{2}}$ in text) $(1.149 \mathrm{~g} ; 10.63 \mathrm{mmol})$ was added dropwise while stirring. The mixture was allowed to stir for 1 $\mathrm{h}$ at room temperature. The product was filtered off as a precipitate, washed with DCM, and dried under vacuum. 1,1'-(1,3-phenylenebis(methylene))bis(3-(pyridin-4-ylmethyl)urea) (paraC in text) was obtained at quantitative yield. The compound was characterized with ${ }^{1} \mathrm{H}$ NMR (Fig. S3a), ${ }^{13} \mathrm{C}$ NMR (Fig. S3b), FTIR (Fig. S3c), DSC (Tm), and MS (ESI).

${ }^{1} \mathrm{H}$ NMR $\left(400 \mathrm{MHz}\right.$, DMSO- $\left.d_{6}\right) \delta=4.22(\mathrm{~d}, \mathrm{~J}=6.02 \mathrm{~Hz}, 4 \mathrm{H}), 4.25(\mathrm{~d}, \mathrm{~J}=6.02 \mathrm{~Hz}), 6.51-6.64$ (m, 4 H), 7.09 - $7.18(\mathrm{~m}, 3 \mathrm{H}), 7.18-7.30(\mathrm{~m}, 5 \mathrm{H}), 8.48(\mathrm{~d}, \mathrm{~J}=5.80 \mathrm{~Hz}, 4 \mathrm{H})$

${ }^{13} \mathrm{C}$ NMR (100 MHz, DMSO- $\left.d_{6}\right) \delta=42.2,43.2,122.1,125.5,125.9,128.4,141.0,149.6,150.3$, 158.2 
FTIR $\left(\mathrm{cm}^{-1}\right): v=3315(\mathrm{~s}, \mathrm{~N}-\mathrm{H}$ stretch$) ; 1623(\mathrm{C}=\mathrm{O}$ stretch $) ; 1577(\mathrm{~N}-\mathrm{H}$ bend $)$

$\mathrm{T}_{\mathrm{m}:}: 191^{\circ} \mathrm{C}$

MS (ESI) m/z: Calculated mass for $\mathrm{C}_{22} \mathrm{H}_{24} \mathrm{~N}_{6} \mathrm{O}_{2}$ : 404.20; Found mass: $405.1[\mathrm{M}+\mathrm{H}]^{+}$

Synthesis of bis-urea compound ortho-C (1,1'-(1,3-phenylenebis(methylene))bis(3-(pyridin-

2-ylmethyl)urea)). A flame dried two-neck flask was charged with dry DCM and 1,3bis(isocyanatomethyl)benzene ( $m$-xylylene diisocyanate, $\mathbf{B}$ in text) $(1 \mathrm{~g} ; 5.31 \mathrm{mmol})$ under nitrogen atmosphere. Pyridin-2-ylmethanamine (2-picolylamine, $\mathbf{A}_{0}$ in text) (1.149 g; $10.63 \mathrm{mmol}$ ) was added dropwise while stirring. The mixture was allowed to stir for $1 \mathrm{~h}$ at room temperature. The product was filtered off as a precipitate, washed with DCM, and dried under vacuum. 1,1'(1,3-phenylenebis(methylene))bis(3-(pyridin-2-ylmethyl)urea) (ortho-C in text) was obtained at quantitative yield. The compound was characterized with ${ }^{1} \mathrm{H}$ NMR (Fig. S4a), ${ }^{13} \mathrm{C}$ NMR (Fig. S4b), FTIR (Fig. S4c), DSC ( $\mathrm{T}_{\mathrm{m}}$ ), and MS (ESI).

${ }^{1} \mathrm{H}$ NMR (600 MHz, DMSO- $\left.d 6\right) \delta=4.23(\mathrm{~d}, \mathrm{~J}=6.05 \mathrm{~Hz}, 4 \mathrm{H}), 4.33$ (d, J=5.87 Hz, $\left.4 \mathrm{H}\right), 6.43$ (br t, $\mathrm{J}=5.50 \mathrm{~Hz}, 2 \mathrm{H}), 6.48(\mathrm{brt}, \mathrm{J}=5.59 \mathrm{~Hz}, 2 \mathrm{H}), 7.13$ (d, J=7.52 Hz, $3 \mathrm{H}), 7.13-7.26$ (m, 5 H), 7.72 (td, J=7.61, $1.65 \mathrm{~Hz}, 2 \mathrm{H}), 8.48($ br d, J=4.59 Hz, $2 \mathrm{H}$ )

${ }^{13} \mathrm{C}$ NMR $\left(150 \mathrm{MHz}, \mathrm{DMSO}-d_{6}\right) \delta=42.9,44.8,120.7,121.5,125.1,125.6,127.8,136.2,140.5$, $148.4,157.8,159.4$

FTIR $\left(\mathrm{cm}^{-1}\right): v=3308(\mathrm{~N}-\mathrm{H}$ stretch$) ; 1621(\mathrm{C}=\mathrm{O}$ stretch$) ; 1568(\mathrm{~N}-\mathrm{H}$ bend $)$

$\mathrm{T}_{\mathrm{m}}: 117^{\circ} \mathrm{C}$

MS (ESI) m/z: Calculated mass for $\mathrm{C}_{22} \mathrm{H}_{24} \mathrm{~N}_{6} \mathrm{O}_{2}$ : 404.20; Found mass: $405.0[\mathrm{M}+\mathrm{H}]^{+}$ 
Gelation procedures. To form $0.8 \mathrm{wt} . \%$ or $1 \mathrm{wt} . \%$ hydrogels, a screw capped vial was filled with meta-C (8 mg or $10 \mathrm{mg}$, respectively) and $1 \mathrm{~mL}$ of deionized water, phosphate buffered saline (PBS), Dulbecco's Modified Eagle's Medium (DMEM), or growth medium. The solid was dispersed by sonicating the vial in a CPX2800H-E ultrasonic bath (Branson) and then heated in a copper block at $100{ }^{\circ} \mathrm{C}$ until complete dissolution. The solution was sonicated using a UP50H Ultrasonic processor with MS1 tip (Hielscher) operating at $30 \mathrm{KHz}(\mathrm{P}=0.075$ W) while cooling down to room temperature to form the hydrogels (Supplementary Movie 1, $\left.\mathrm{ESI}^{\dagger}\right)$.

Scanning Electron Microscopy (SEM) measurements. A screw capped vial was charged with $8 \mathrm{mg}$ of compound and $1 \mathrm{~mL}$ of $\mathrm{H}_{2} \mathrm{O}$ (MilliQ). The solid was dispersed by sonicating the vial in a CPX2800H-E ultrasonic bath, and the vial was heated to $100{ }^{\circ} \mathrm{C}$ until the compound dissolved. Next, the solution was allowed to cool to room temperature under sonication using a Hielscher UP50H Ultrasonic processor with MS1 tip operating at $\mathrm{P}=0.075 \mathrm{~W}$. When at room temperature, the vial was submerged into liquid nitrogen to freeze the sample completely. The frozen sample was lyophilized to obtain either a xerogel from $\boldsymbol{m e t a - C}$ or a dried precipitate from ortho-C and para-C. This solid was placed on carbon tape attached to a SEM sample holder and coated with Pd/Pt or Pt using a high-resolution Quorum Sputter coater (Q150T S). The coated sample was placed under high vacuum overnight prior to imaging. The SEM images were acquired using a SEM XL 30 FEG (Philips) with the following imaging parameters: Acc.V $=10.0 \mathrm{kV}$; Spot $=3.0$; Magn. $=5000 \mathrm{x} / 20000 \mathrm{x} / 5000 \mathrm{x}$ (for Fig. 3a, b, c, respectively); Det. $=$ SE; WD = 7.2/7.3/7.2 (for Fig. 3a, b, c, respectively); Exp. $=1$.

Atomic Force Microscopy (AFM) measurements. Hydrogels of $\boldsymbol{m e t a}$-C were prepared at 0.8 wt.\% in deionized water or growth medium as described above. $100 \mu \mathrm{L}$ of the hydrogels were further diluted in $1 \mathrm{~mL}$ of deionized water, and the suspension was sonicated using a Hielscher 
UP50H Ultrasonic processor with MS1 tip to disperse the hydrogel in the water. The samples (20 $\mu \mathrm{L}$ ) were deposited on freshly cleaved mica plates, dried, and imaged using a JPK Nanowizard ${ }^{\circledR}$ III Bioscope in contact mode (Probe: NSC35/Al BS; spring constant $=16 \mathrm{~N} / \mathrm{m}$; tip radius $\sim 8 \mathrm{~nm}$; rectangular geometry with a length of $90 \mu \mathrm{m}$, width of $35 \mu \mathrm{m}$, and thickness of $2 \mu \mathrm{m}$ ). All of the recorded AFM images consisted of either 512 x 512 or 1024 x 1024 pixels with XY scan size varying from $1 \times 1 \mu \mathrm{m}^{2}$ to $10 \times 10 \mu \mathrm{m}^{2}$. AFM images were obtained at multiple locations across the surface of 3 sample preparations to ensure the reproducibility of the results. Bundled or crossing nanofibrils as well as nanofibrils that appeared fragmented were excluded from the width and height analysis. Line profile analysis was performed on the nanofibrils/nanofibers randomly, and the height and width values were calculated as shown in Fig. S5. Width determination of the individual nanofibrils might not reflect the actual width of the nanofibrils because the width measurement is dependent on the size and shape of the AFM tip, ${ }^{1}$ and therefore the reported width values of the nanofibrils should only be compared relative to each other. For the height and width correlation, nanofibrils/nanofibers were binned based on height measurements, in increments of $2 \mathrm{~nm}$. Nanofibrils with $0-1.9 \mathrm{~nm}$ height were the first group, nanofibrils with $2-3.9 \mathrm{~nm}$ height were the second group, nanofibrils with $4-5.9 \mathrm{~nm}$ were the third group, and so on. A linear fit through the measured data was made.

Variable-Temperature (VT) NMR measurements. A screw capped vial was charged with 8 mg of meta-C, $0.9 \mathrm{~mL}$ of $\mathrm{H}_{2} \mathrm{O}$, and $0.1 \mathrm{~mL}$ of $\mathrm{D}_{2} \mathrm{O}$, and the solid was dispersed by sonicating the vial in an ultrasound bath. The vial was heated in a copper block at $100{ }^{\circ} \mathrm{C}$ until a clear solution was obtained. The solution was pipetted from the vial using a preheated Pasteur pipet and transferred to a preheated NMR tube. 3-(Trimethylsilyl)propionic-2,2,3,3- $d_{4}$ acid sodium salt dissolved in $\mathrm{D}_{2} \mathrm{O}(3 \mathrm{mM})$, as an external standard, was placed in an insert tube inside the NMR tube, after 
which the tubes were sonicated in an ultrasonic bath while cooling to induce gelation. VT ${ }^{1} \mathrm{H}$ NMR spectra were recorded on a Bruker Avance 600 spectrometer operating at $600 \mathrm{MHz}$. Spectra were acquired at $30{ }^{\circ} \mathrm{C}, 40{ }^{\circ} \mathrm{C}, 50{ }^{\circ} \mathrm{C}, 60{ }^{\circ} \mathrm{C}, 70{ }^{\circ} \mathrm{C}, 80{ }^{\circ} \mathrm{C}$, and $90{ }^{\circ} \mathrm{C}$.

Rheology measurements. Cylindrical hydrogels were prepared using a plastic syringe and measured on a MCR 501 Rheometer (Anton-Paar). Samples were prepared via the following procedure. A screw capped vial was charged with $8 \mathrm{mg}$ of $\boldsymbol{m e t a}-\mathbf{C}$ and $1 \mathrm{~mL}$ of growth medium. The vial was sonicated until the gelator was dispersed over the liquid and subsequently heated at $100{ }^{\circ} \mathrm{C}$ until the gelator dissolved. The supersaturated solution was poured into a syringe with a cut off tip (Fig. S6). The solution was allowed to cool to room temperature under ultrasound irradiation using a Hielscher UP50H Ultrasonic processor with MS1 tip operating at $\mathrm{P}=0.075$ W. The hydrogels were stored overnight at $6.7^{\circ} \mathrm{C}$. A slice of the hydrogel was placed on the rheometer surface. The rheometer probe $(8 \mathrm{~mm}$ diameter) was lowered to $1.5 \mathrm{~mm}$, and the excess hydrogel was trimmed. The final sample volume was $75 \mathrm{~mm}^{3}$.

Strain sweep measurements were performed by varying the applied strain between 0.01 and $10 \%$ at a constant angular frequency of $6.28 \mathrm{rad} / \mathrm{s}$ and a constant temperature of $37{ }^{\circ} \mathrm{C}$. Frequency sweep measurements were performed by varying the angular frequency between 10 and 0.1 $\mathrm{rad} / \mathrm{s}$ at a constant strain of $0.08 \%$ and a constant temperature of $37{ }^{\circ} \mathrm{C}$. A first dynamic strain amplitude test was performed by systematically applying a strain of $10 \%$ on the sample for $30 \mathrm{~s}$ followed by a strain of $0.08 \%$ for period of $5 \mathrm{~min}$, to let the hydrogel recover. During the measurement, the temperature was kept constant at $37{ }^{\circ} \mathrm{C}$, and the angular frequency was kept constant at $6.28 \mathrm{rad} / \mathrm{s}$. A second dynamic strain amplitude test was performed by systematically applying a strain of $100 \%$ on the sample for $60 \mathrm{~s}$ followed by a strain of $0.08 \%$ for period of $100 \mathrm{~s}$, to let the hydrogel recover. During the measurement, the temperature was kept constant at $37^{\circ} \mathrm{C}$, and the angular 
frequency was kept constant at $6.28 \mathrm{rad} / \mathrm{s}$. Data processing of the rheological measurements was performed using GraphPad Prism 7.05 to obtain the average and standard deviation of three sets of data.

Cell culture. L929 fibroblasts (mouse C3H/AN connective tissue, Sigma Aldrich) at passage 7 were cultured in standard tissue culture flasks at $37{ }^{\circ} \mathrm{C}$ in humidified air mixed with $5 \% \mathrm{CO}_{2}$ in a growth medium consisting of DMEM (Invitrogen) mixed with $10 \%$ fetal bovine serum (FBS; Invitrogen) and $1 \%$ antibiotics (Invitrogen). Cells were subcultured when they reached about 75 $\%$ confluence, and the medium was changed every $3 \mathrm{~d}$.

Cell encapsulation. To encapsulate the cells for culture in 3D in the hydrogels, $\boldsymbol{m e t a}$-C was first introduced into a glass vial and sterilized under UV light for $20 \mathrm{~min}$. Then, sterile growth medium was added, and hydrogels at 1 wt.\% were prepared as previously described. L929 fibroblasts at passage 8 were trypsinized using trypsin-EDTA $(0.25 \%$ with phenol red, Thermo Fisher Scientific) and resuspended in growth medium. Cells were stained with trypan blue, and the viable cell concentration was determined using a hemocytometer (Bruker). Cells, to achieve a final seeding density of $1.2 \times 10^{6} \mathrm{cells} / \mathrm{mL}$, were then mixed with the hydrogels, to achieve a final concentration of $0.8 \mathrm{wt} . \%$, using a syringe. The hydrogels containing cells, each $1 \mathrm{~mL}$ in volume, were transferred to standard tissue culture-treated well plates for the proliferation and viability assays or to glass bottom well plates for imaging of cell morphology. The well plates were then incubated for $48 \mathrm{~h}$ in an incubator at $37{ }^{\circ} \mathrm{C}$ with humidified air mixed with $5 \% \mathrm{CO}_{2}$.

Evaluation of cell morphology. At selected time points ( 2 h, 24 h, and 48 h), the hydrogels (in duplicate) were washed with PBS, and the cells were fixed and permeabilized with a paraformaldehyde (PFA)/Triton X100 solution (4 \% PFA + $0.2 \%$ Triton X100 in PBS) for 40 $\min$ 
at room temperature. The PFA solution was then removed, and glycine $(0.1 \mathrm{M})$ was added for 15 min at room temperature. The glycine solution was removed, and the hydrogels containing cells were washed 2 times with PBS and stained with AlexaFluor 488 phalloidin (2 U/mL in PBS) and DAPI $(2.5 \mu \mathrm{g} / \mathrm{mL})$ for $2 \mathrm{~h}$. The hydrogels were then washed 2 times with PBS. Z-stacked confocal images of the stained cells were acquired using a Zeiss LSM 780 confocal microscope with $488 \mathrm{~nm}$ and $405 \mathrm{~nm}$ laser lines for AlexaFluor 488 phalloidin and DAPI excitation, respectively. For the widefield images, a $25 \times$ water immersion lens (0.8 N.A.) was used for scanning a depth of $100 \mu \mathrm{m}$ with a $5 \mu \mathrm{m}$ step size. The magnified inset images were acquired using a $63 \times$ water immersion lens (1.15 N.A.) and step size of $\sim 0.8 \mu \mathrm{m}$.

Cell proliferation and viability assays. At each time point $(2 \mathrm{~h}, 24 \mathrm{~h}$, and $48 \mathrm{~h}), 1 \mathrm{~mL}$ of additional growth medium was added into the wells (4 replicates) and gently mixed with the hydrogels to disperse the cells. The harvested cells were then stained with trypan blue and counted using a hemocytometer. The number of live and dead cells was recorded, and the data were processed using GraphPad Prism 5 software.

Statistical analysis. Data for cell proliferation, viability, and circularity (calculated as the ratio between minor and major axes within the perimeter of the F-actin signal for each cell, with 1 indicating a perfectly round cell) were analyzed by calculating the mean and standard deviation of $\mathrm{n}=4$ or 5 , as indicated in the figure captions. A one-way ANOVA with Bonferroni's multiple comparisons test was used to assess the effect of time with $p<0.05$ considered to indicate statistical significance (GraphPad Prism 5). 


\section{Supplementary Movies}

Supplementary Movie 1: Gel preparation procedure. First, $1 \mathrm{~mL}$ of growth medium is added to a vial containing $8 \mathrm{mg}$ of meta-C. Second, the vial is heated in a copper block at $100{ }^{\circ} \mathrm{C}$ until the gelator is fully dissolved. Next, the vial is opened, and the solution is sonicated using a UP50H Ultrasonic processor with MS1 tip operating at $30 \mathrm{KHz}(\mathrm{P}=0.075 \mathrm{~W})$. While cooling down to room temperature, the gel forms. Finally, the vial is capped and inverted to confirm gelation.

Supplementary Movie 2: Illustration of the injectability of the hydrogel. A 0.8 wt.\% hydrogel made with growth medium is pushed through a syringe equipped with a needle (0.90 $\mathrm{mm}$ in diameter). The gel flows when stress is applied and restores at the surface of the container, after which the container is inverted to demonstrate the gel state. 


\section{Supplementary Figures}

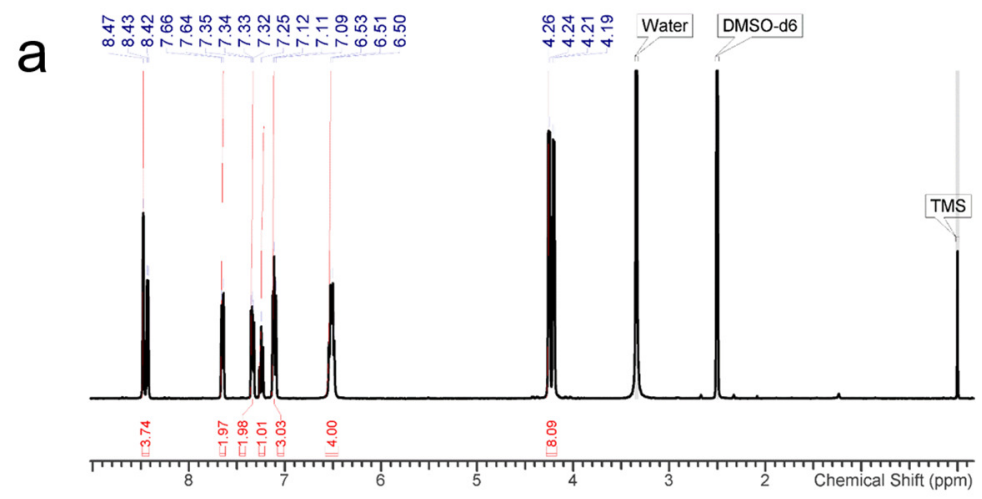

b

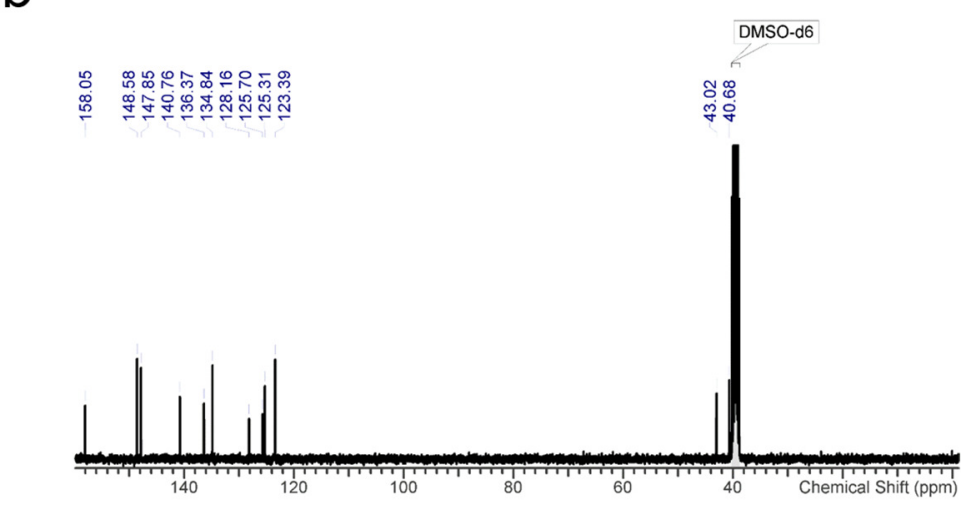

C
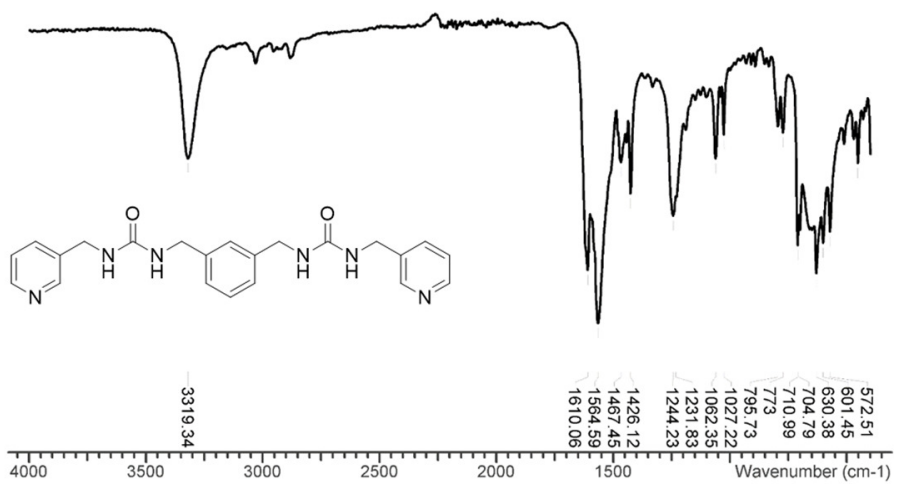

Fig. S1 Chemical characterization of 1,1'-(1,3-phenylenebis(methylene))bis(3-(pyridin-3ylmethyl)urea) (meta-C) prepared in solution. (a) ${ }^{1} \mathrm{H}$ NMR spectrum, with the peaks of the $\mathrm{CH}_{2}$ between 4.26 and $4.19 \mathrm{ppm}$, peaks of the urea NH between 6.53 and $6.50 \mathrm{ppm}$, and peaks of the aromatic protons between 8.47 and $7.09 \mathrm{ppm}$; (b) ${ }^{13} \mathrm{C}$ NMR spectrum, with the carbonyl peak of the urea group at $158.1 \mathrm{ppm}$; and (c) FTIR spectrum, with main peaks at $3319 \mathrm{~cm}^{-1}$ (N-H stretch), $1610 \mathrm{~cm}^{-1}\left(\mathrm{C}=\mathrm{O}\right.$ stretch), and $1565 \mathrm{~cm}^{-1}$ (N-H bend). Inset shows the chemical structure of metaC. 
a
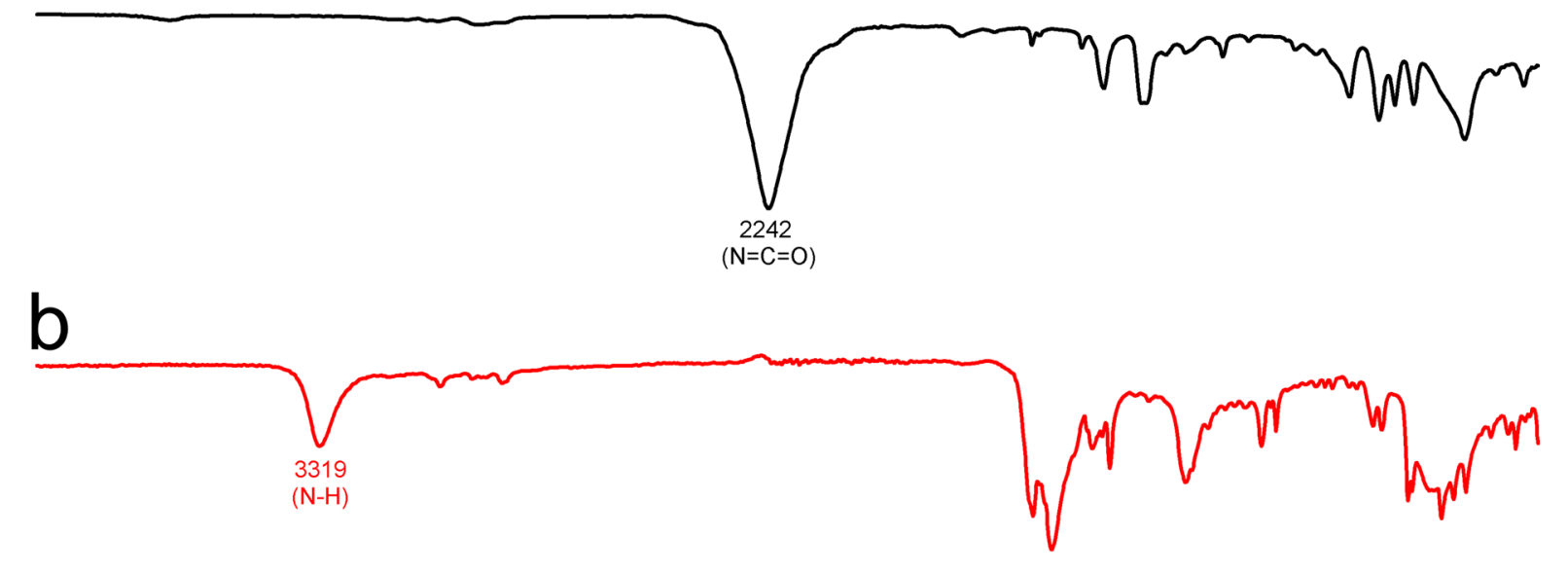

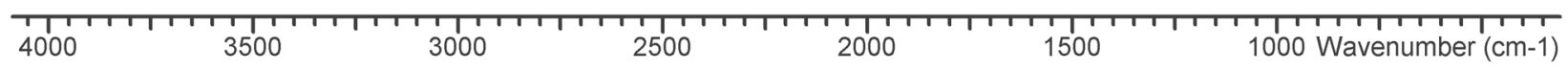

Fig. S2 FTIR spectra showing the conversion of the starting material into meta-C via the ball milling method. (a) FTIR spectrum of 1,3-bis(isocyanatomethyl)benzene ( $m$-xylylene diisocyanate, $\mathbf{B}$ in text) with a peak at $2242 \mathrm{~cm}^{-1}$, indicating the presence of an isocyanate functional group. (b) FTIR spectrum of 1,1'-(1,3-phenylenebis(methylene))bis(3-(pyridin-3ylmethyl)urea) (meta-C) where the peak at $2242 \mathrm{~cm}^{-1}$ has disappeared, indicating full conversion of the starting material. 


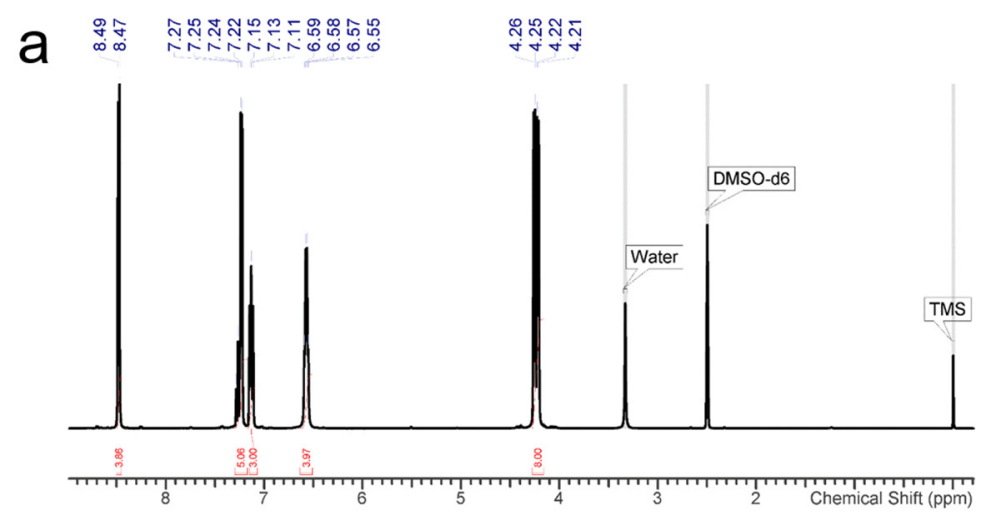

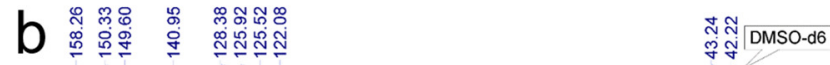
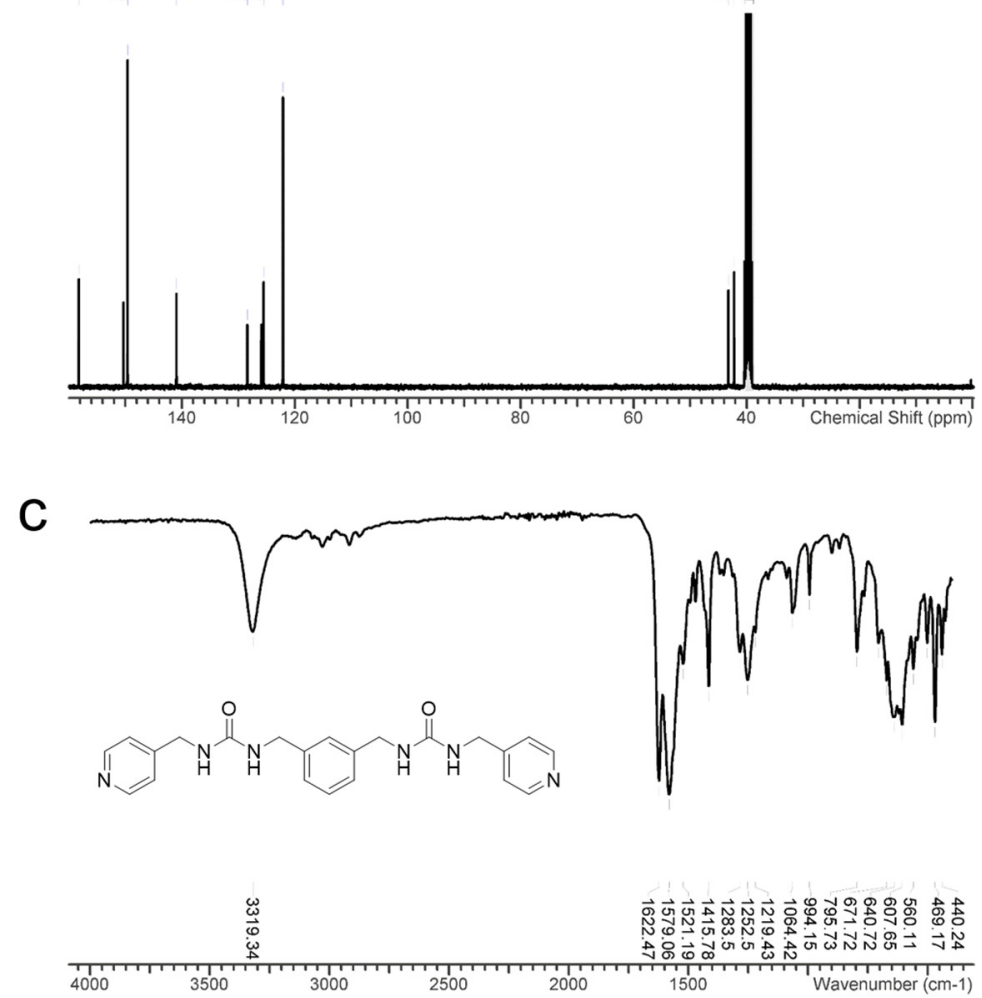

Fig. S3 Chemical characterization of 1,1'-(1,3-phenylenebis(methylene))bis(3-(pyridin-4ylmethyl)urea) (para-C). (a) ${ }^{1} \mathrm{H}$ NMR spectrum, with the peaks of the $\mathrm{CH}_{2}$ between 4.26 and 4.21 ppm, peaks of the urea NH between 6.59 and $6.55 \mathrm{ppm}$, and peaks of the aromatic protons between 8.49 and $7.11 \mathrm{ppm}$; (b) ${ }^{13} \mathrm{C}$ NMR spectrum, with the carbonyl peak of the urea group at $158.3 \mathrm{ppm}$; and (c) FTIR spectrum, with main peaks at $3319 \mathrm{~cm}^{-1}$ (N-H stretch), $1622 \mathrm{~cm}^{-1}(\mathrm{C}=\mathrm{O}$ stretch), and $1579 \mathrm{~cm}^{-1}$ (N-H bend). Inset shows the chemical structure of para-C. 

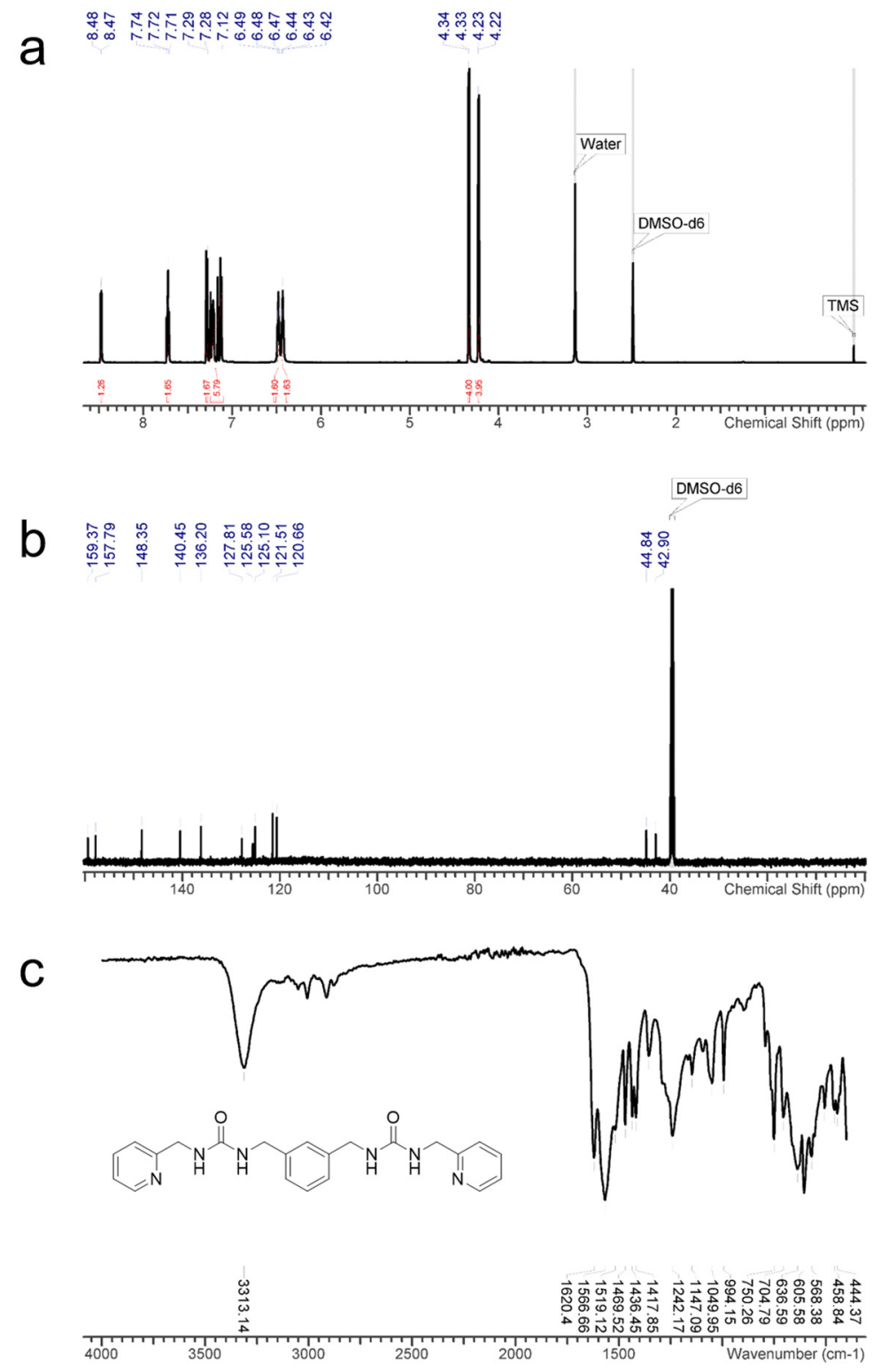

Fig. S4 Chemical characterization of 1,1'-(1,3-phenylenebis(methylene))bis(3-(pyridin-2ylmethyl)urea) (ortho-C). (a) ${ }^{1} \mathrm{H}$ NMR spectrum, with the peaks of the $\mathrm{CH}_{2}$ between 4.34 and 4.22 ppm, peaks of the urea NH between 6.49 and $6.42 \mathrm{ppm}$, and peaks of the aromatic protons between 8.48 and $7.12 \mathrm{ppm}$; (b) ${ }^{13} \mathrm{C}$ NMR spectrum, with the carbonyl peak of the urea group at $159.4 \mathrm{ppm}$; and (c) FTIR spectrum, with main peaks at $3313 \mathrm{~cm}^{-1}\left(\mathrm{~N}-\mathrm{H}\right.$ stretch), $1620 \mathrm{~cm}^{-1}$ (C=O stretch), and $1567 \mathrm{~cm}^{-1}$ (N-H bend). Inset shows the chemical structure of ortho-C. 

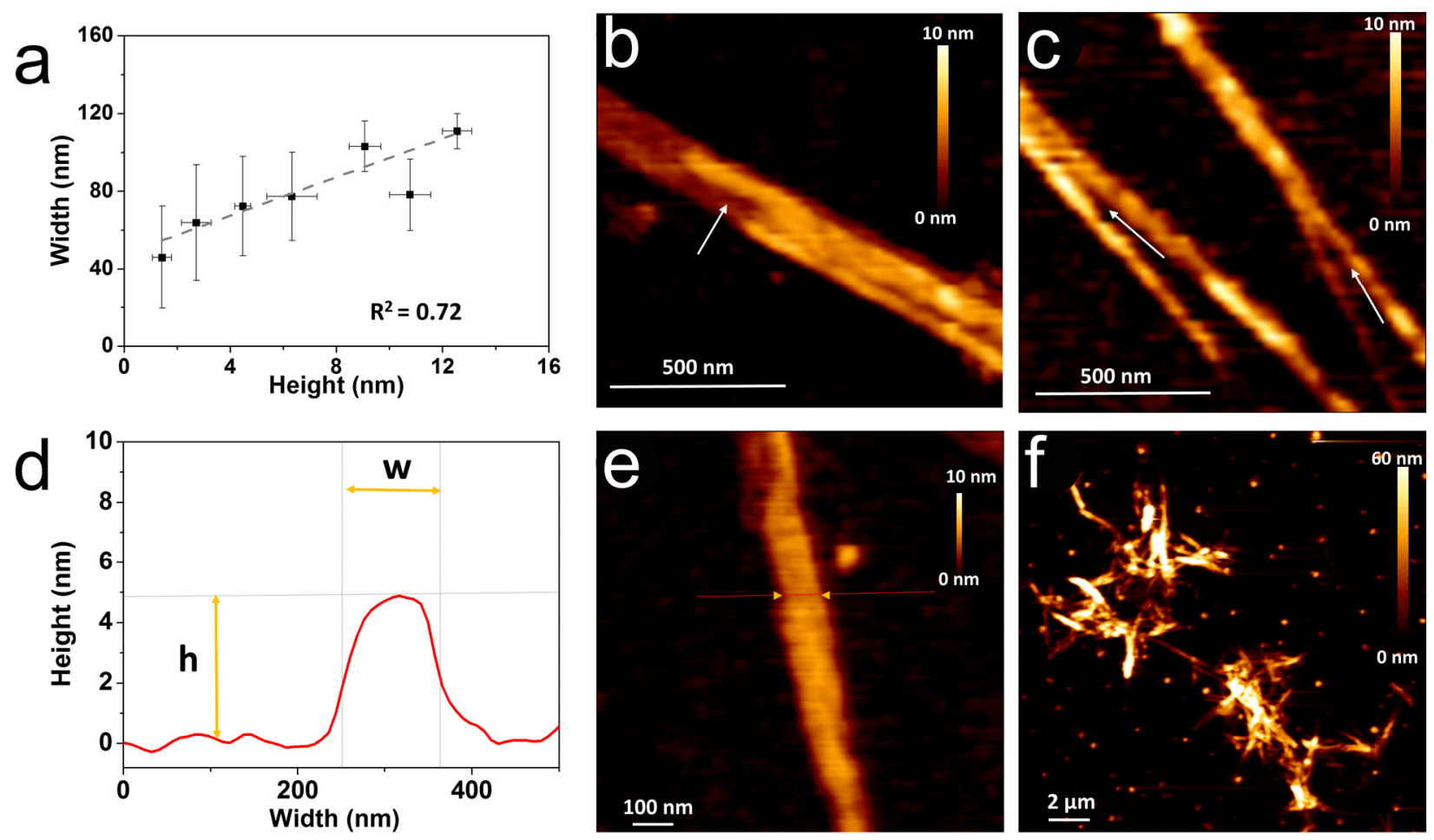

Fig. S5 Detailed AFM structural analysis. (a) Height and width correlation of measured individual nanofibrils of meta-C $(n=169)$. Nanofibrils were grouped based on height measurements with a bin size of $2 \mathrm{~nm}$. Average height and width of the corresponding groups are shown (whiskers indicate standard deviation). The dotted line indicates a linear fit through the measured data, $\mathrm{R}^{2}>$ 0.7. (b) An example AFM image of meta-C showing nanofibril stacking/thinning on top of other nanofibrils (indicated by white arrow mark). Scale bar is $500 \mathrm{~nm}$, and Z-scale bar is 0-10 nm. (c) An example AFM image of meta-C showing nanofibril splitting (indicated by white arrow marks). Scale bar is $500 \mathrm{~nm}$, and Z-scale bar is $0-10 \mathrm{~nm}$. (d) Line profile measurement of AFM width and height analysis of the nanofibril of meta-C shown in (e) (measured location indicated by red line with yellow arrow marks to indicate the measured width). Scale bar is $100 \mathrm{~nm}$, and Z-scale bar is 0-10 nm. (f) AFM image showing the formation of nanofibrils/nanofibers of meta-C in growth medium. Scale bar is $2 \mu \mathrm{m}$, and Z-scale bar is $0-60 \mathrm{~nm}$. 

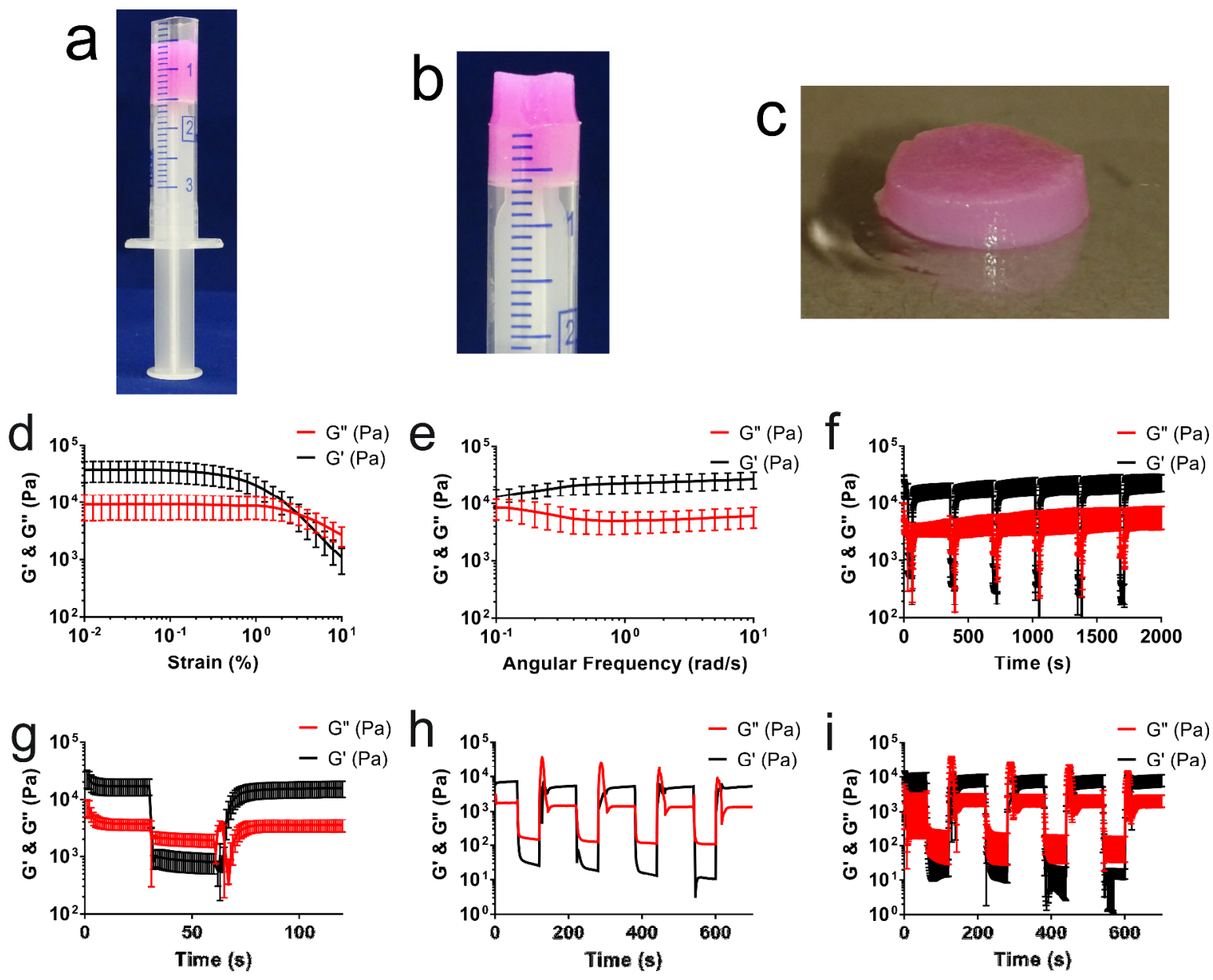

Fig. S6 Sample preparation for rheology, rheology graphs with error bars, and additional rheology graphs. (a) The hydrogel (0.8 wt.\% meta-C in growth medium) was prepared in a syringe with the tip cut off; (b) the cylindrical hydrogel was pushed out of the syringe; and (c) a disk-shaped part of the hydrogel was cut off using a spatula and placed on the rheometer. (d-g) Graphs of rheology data shown in main text including error bars (average and standard deviation of three independent measurements) with (d) strain sweep (at an angular frequency of $6.28 \mathrm{rad} / \mathrm{s}$ ); (e) frequency sweep (at a strain of $0.08 \%$ ); and (f, g) dynamic strain amplitude test (alternating between $0.08 \%$ and $10 \%$ strain at an angular frequency of $6.28 \mathrm{rad} / \mathrm{s}$ ). (h, i) Dynamic strain amplitude test performed on 0.8 wt.\% hydrogels of meta-C made with growth medium. Rheology was performed at an angular frequency of $6.28 \mathrm{rad} / \mathrm{s}$ and temperature of $37^{\circ} \mathrm{C}$. The strain was alternated between 0.08 $\%(100 \mathrm{~s})$ and $100 \%(60 \mathrm{~s})$. When the strain changes from $0.08 \%$ to $100 \%$, the values of the storage modulus ( $G^{\prime}$ ) fall below the values of the loss modulus ( $\left.G^{\prime \prime}\right)$, indicating the disruption of the gel network. When the strain changes back to $0.08 \%$, the values of the storage modulus increase again to their original value, indicating the recovery of the gel properties. (h) average of three independent measurements and (i) average and standard deviation of the same three independent measurements. 


\section{References for Supplementary Information}

1. Y.-C. Lin, H. Komatsu, J. Ma, P. H. Axelsen and Z. Fakhraai, $R S C$ Adv., 2016, 6, 114286. 


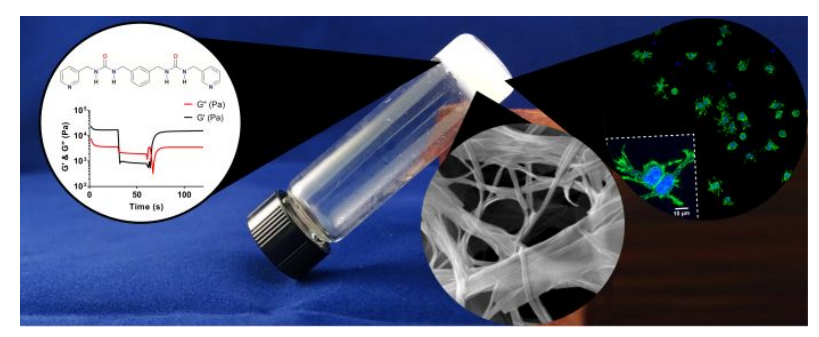

Cytocompatible nanofibrous thixotropic supramolecular hydrogel based on a low molecular weight bis-urea scaffold 